\title{
Prevalence and Associated Factors of Pneumonia among Children 2 - 59 Months of Age in Gumay District, Jimma Zone, Southwest Ethiopia
}

\section{Anteneh Tesfaye}

Gumay District Health Office

\section{Desta Hiko}

Jimma University Institute of Health, Epidemiology Department

Teshome Kabeta ( $\nabla$ tka1204@gmail.com )

Jimma University https://orcid.org/0000-0003-0749-8908

Research article

Keywords: Children Aged 2months to Five years, Pneumonia, cross sectional, under five

Posted Date: July 10th, 2019

DOl: https://doi.org/10.21203/rs.2.11138/v1

License: (c) (i) This work is licensed under a Creative Commons Attribution 4.0 International License.

Read Full License 


\section{Abstract}

Background Recent estimates from the World Health Organization suggest that pneumonia is responsible for $20 \%$ of deaths in the under-five age group, leading to 3 million deaths per year. Out of fifteen countries that have the highest death rate from clinical pneumonia in children younger than five-year-old, Ethiopia ranks as number four in the world. Objective To determine the prevalence and identify the associated factors of pneumonia among 2 -59 months old children in Gumay district, Jimma zone, 2017. Methods Community based cross sectional study was conducted in Gumay district from March 1-26/2017. Multistage sampling technique was used to proportionally draw 347 households from 5 selected kebeles. Pretested Interviewer administered structured questionnaire was employed to collect data from households. Health professionals were recruited in the survey as data collectors and supervisors. The data was entered to Epi-Data version 3 and then exported to SPSS version 20 for analysis. Result The prevalence of pneumonia in 2 to 59 months old children found to be 7.5\%. a child 2-11 months of age(AOR = 3.17;95\% Cl 1.6,6.3; $p$-value $=0.024)$, Cooking place (AOR=5.7; 95\% Cl 1.83,18; $p$-value $=0.004)$, living in houses with less than two windows $(A O R=3.18 ; 95 \% \mathrm{Cl} 1.07,9.5 ; p$-value $=0.034)$, location of the child during cooking $(A O R=5.15 ; 95 \% \mathrm{Cl} 1.6,16.7 ; p$-value $=0.008)$ and being not vaccinated $(A O R=4.76,95 \%$ $\mathrm{Cl} ; 1.69,13.37$; $\mathrm{p}$-value=0.003) were found to be significant associated with pneumonia among children 2 to 59 months of age in this study.

\section{Background}

Pneumonia is the lower respiratory tract infection that exclusively affects the lung. While it attacks every person, children under the age of five years are particularly prone to pneumonia (1). The incidence of pneumonia in children younger than five is 0.29 episodes per year. 151.8 million Cases are recorded annually in developing countries. 4 million cases are recorded annually in developed countries. A range of both bacterial and viral pathogens have been recognized to cause pneumonia in children with streptococcus pneumoniae accountable for the vast majority of cases (1).

Pneumonia is the single leading cause of death among children younger than five years in Ethiopia. It was estimated that $3,370.000$ children encounter pneumonia annually which contributes to $20 \%$ of all causes of deaths killing over 40,000 under five children every year and leading cause of death during postnatal period (2). In Ethiopia, there are very few studies carried out so far on the prevalence of pneumonia and its risk factors and, as well, with one or more methodological weakness. Evidence showed that different factors were associated with occurrence of under-five pneumonia. Factors could be child, maternal, environmental, access to health care, overcrowding, indoor air pollution, Charcoal use for cooking, carrying the child on back during cooking, cooking within the main house, Co morbid diseases such as HIV/AIDS, Malaria, Exclusive breast feeding, duration of breast feeding as well as nutritional status of the child (3).

The determinants of pneumonia are numerous - educational status of parents, smoking habits of any member of the household, nutritional status, age and sex of the child- and widely vary across the regions 
of the world. The clinical picture of pneumonia differs depending on the micro organism causing the disease and age of a child. Pneumonia in children with high grade fever and difficulty of breathing is usually caused by bacterial pathogens and pneumonia due to viral causes often comes about progressively(1). Timely diagnosis of pneumonia is an essential step in the prevention process of the diseases. X-ray and laboratory identification of the causative agent are the confirmatory tools to certainly establish the diagnosis of pneumonia. However, these are largely unaffordable in the resource poor settings like Ethiopia.

The recommended approach to settle the diagnosis of suspected pneumonia in such regions is, therefore, to rely on the clinical presentation of the disease (4). To this end, Integrated Management of Neonatal and Childhood Illness (IMNCI) has been launched by the World Health Organization (WHO) and United Nation's Children Fund (UNICEF) to help health workers classify and treat pneumonia and other most common childhood illness based on certain sensitive and specific signs. The core of this innovative prevention and curative strategy is to approach the sick child in an integrated fashion, instead of targeting on single diseases for which $\mathrm{s} /$ he has been brought, the child is assessed holistically for possible common childhood problems such as pneumonia, Diarrhea, Malaria ,Malnutrition and others (4)

The presence of cough and fast breathing and or difficulty of breathing for specific age clench the classification of suspected pneumonia in children older than 2 months and yet less than 60 months of age (4). Any children older than 2 months of age who presents with one or more of the following danger sign is classified as having suspected sever pneumonia or diseases: chest in drawing, stridor, convulsion, vomiting everything, inability to breast feed/eat/drink, unconsciousness, and lethargy (4). Its effectiveness in detecting the suspected pneumonia cases, based on these sensitive and specific signs, and hence its aid in prescribing appropriate medication, has been assured to date (4).

\section{Methods}

To assess the prevalence and associated factors of Pneumonia among 2 -59 months old children a community based cross sectional study was conducted from March $1-26 / 2017$.The study was carried out in Gumay district, Jimma zone, Oromiya regional state, south west of Ethiopia. The district has a total population of 75,490 that reside in 13 rural and two urban kebeles with total households of 15,726 . The number of under five year children constitutes $16.43 \%$ of the total population of the district. Pneumonia is the single leading cause of death among children younger than five years in Ethiopia. Pneumonia is the second of the top ten causes of morbidity of pediatrics which constitute more than $26 \%$ of the total outpatient cases in the district.

Study population

The study population were children in the age group of 2 to 59months and mothers/care takers pair who fulfill the inclusion criteria and living in the selected kebeles. 
Children 2-59 months of age and primary caretaker's pairs who were living in the selected kebeles were included in the study and Mothers/caretakers who were severely ill, had hearing impairments or unable to talk were excluded.

Variables- Pneumonia status of the child based on clinical diagnosis was the dependent variable and Socio demographic characteristics, environmental characteristics, history of breast-feeding status and current nutritional status of the child, immunization status of the child and health seeking behavior of parents/care takers were independent variables of the study.

Sample size- A total of 347 households were included in the study by determining the number study subjects using Single population proportion formula by considering the prevalence of pneumonia among under- five year children to be $12.7 \%(5)$, level of confidence $95 \%$, and margin of error $5 \%$, the sample size is calculated as follows:

\section{Sample size $=\underline{Z a^{2}} \stackrel{*}{*} \underline{p} * \underline{q}$ \\ $d^{2}$}

Where: -

- p- proportion of pneumonia cases, $\mathrm{P}=12.7$

- $\mathbf{q}$-Proportion of children who have no pneumonia, $q=87.3$

- $\mathbf{Z}_{\mathbf{a}}$ represents standard normal variable at (1-a) \% confidence level with a level of significance, $a$ taken to be $5 \%$ and $Z_{a}$ is 1.96

- W-margin of error, $5 \%$

Substituting the values for each of these variables in the above formula,

Sample size $=(\underline{1.96}) \underline{\underline{2} * 0.127 * 0.873}=170$

$(0.05)^{2}$

The sample size is estimated to be 170 . Adding the potential none response rate of $2 \%$ and multiplying the result by a design effect of 2 , the final sample size will be $\mathbf{3 4 7}$ households having children 2-59 months of age are required.

Multi-stage sampling technique was employed to select participants of the study. The study area first stratified in to Urban and Rural kebeles since residency is known to affect the prevalence of under- five childhood pneumonia. The total 15 kebeles of the study area were stratified in to two strata, urban and rural, each containing two and 13 kebeles, respectively. Then in the first stage, out of the two urban kebeles one urban kebele was selected randomly and out of the 13 rural kebeles four kebeles were 
selected through lottery method. In the third sampling stage, proportional sampling technique of every $\mathrm{K}^{\text {th }}$ interval was used to take households from each of the selected five kebeles.

Interviewer administered structured questionnaire in local language was used to collect data. Health professionals from the study area were recruited to data collection and for supervision. Mothers or caretakers were interviewed deeply about the health status of the child two weeks prior to the study. A child having cough , fast breathing or lower chest in drawing or all of them at the time of the survey, was physically examined to assess his breathing rate and the presence of danger signs namely convulsion, inability to eat/drink, vomiting everything, strider and unusually sleepiness (4). In addition, history of measles infection of the child and the presence of diarrhea during data collection or two weeks prior to the study were assessed. Anthropometric measurement of MUAC of the children was taken. Nutritional status of the children was determined using WHO growth standard to report principal anthropometric results, and the global acute malnutrition standard was used to categorize a child's condition as severe malnutrition, moderate malnutrition and normal nutritional status.

Descriptive analysis was performed and presented by using tables and graphs. Binary and multivariable logistic regression analyses were employed. The variables which have a statistical significance association in the final multivariable analysis were identified based on p-values $<0.05$ and AOR with $95 \%$ confidence intervals at the end.

\section{Results}

Background characteristics of the study participants

The study population consisted of children in the age group of 2 to 59 months and mother's/ primary care takers pair. A total of three hundred forty-seven (347) households were included in the study with a response rate of $100 \%$. Majority of mothers/care takers, $221(75.2 \%)$ and $224(76 \%)$ of the heads of the households were literate. The largest proportion of mothers 189 (54.5\%) and husbands 184 (53\%) were at primary school level in their educational status. The vast majority of the mothers of the study population were housewife in their occupation. More than $52 \%$ of the husbands were farmers. The highest proportion of children in the survey $140(40.3 \%)$ were in the age group of 12-23 months and children in the age group of 2-11 months comprises the smallest percentages, $24 \%$ with the mean age of the child 25.44 months $(S D \pm 9.12)$. One hundred ninety five (56.2\%) of the participant children were male. Out of the total 347 households, 250 (72\%) households were rural dwellers. Many of the households of the study population have an average family size of 4-7 people per household. More than two third of the population use protected springs/hand pumps water sources for all purpose. More than $71 \%$ of the households use unimproved latrine facilities. 205 children (59\%) were breastfed exclusively during the first six month of their life. Regarding previous infection history of the presence of diarrhea two weeks prior to the study and measles infection history of the children were assessed and according to the finding, $90(26 \%)$ children had diarrhea infection less than two weeks prior to the study and 37(10.7\%) children had been affected by measles. Among the total 347 mother who interviewed to assess their knowledge to the 
benefits of vaccines, many of the mothers $80 \%$ were aware to the benefit. More than $82 \%$ of the children have been vaccinated at least once in their lifetime. (Table 1).

The prevalence of 2-59 months old children pneumonia

Among 347 children enrolled in the study, 35(10.1\%) of them had cough during or two weeks prior to the survey, of whom the majority had history of cough for less than two weeks. Thirty-one children had cough and fast breathing and from this 27 of them had chest wall in drawing at the time of the survey. Out of the total children who showed different sign and symptoms that can be related to pneumonia, we determine the classification of the disease of a sick child as pneumonia positive based on the presence of cough, fast breathing and chest in drawing. Based on this, the number children who fulfilled these criteria were taken positive to pneumonia. As a result, the number of children who were positive to pneumonia during the study period was 26 . Therefore, the prevalence of pneumonia among children 0259 months of age in Gumay district at the time of survey was $7.5 \%$.

\section{Determinants of pneumonia}

Child and parental conditions, household and environmental related determinants were analyzed using bivariable logistic regression and all explanatory variables with p-value less than 0.05 in bi variable analysis were entered to multiple variable analysis of binary logistic regression after assumptions of binary logistic regression were checked. In bi-variable logistic regression analyses, 24 variables which were assumed to be associated with pneumonia were analyzed by the enter method of binary logistic regression and variables with $p$-value less than 0.05 significance level were entered into the multiple logistic regression. Fifteen (15) of the 24 explanatory variables (Age of the child, types of latrine facility, place of cooking, number of windows in living house, cleanliness of the house, location of the child during cooking, exclusive breast feeding status, weaning time, nutritional status of the child, history of diarrhea two weeks prior to the study, awareness of mothers'/care takers' on benefits of vaccine, vaccination history and immunization status of the child and health seeking behavior of mother's/care takers) were statistically significantly associated with pneumonia at $p$-value less than 0.05 and considered for further analysis in multivariate logistic regression.(Table 2)

Factors independently associated with pneumonia

Variables that showed significant association in binary logistic regression model were Age of the child, type of latrine, cooking place and separately constructed kitchen, number of windows, cleanliness, location of the child during cooking, breast feeding status, weaning time, nutritional status, history of diarrhea, awareness of vaccine benefits, vaccination status, immunization status and health seeking behavior of the mothers. Age of the child, Regular cooking place, the number of windows, location of the child during cooking and vaccination history of the child remained significantly associated with pneumonia. The survey showed that children 2-11 months of age are about three times (AOR=3.17; 95\% $\mathrm{Cl} 1.6,6.3)$ more likely to develop pneumonia than children $24-59$ months of age. The odds of pneumonia among children living in houses where food regularly cooked in main house was six times (AOR=5.7; $95 \%$ 
$\mathrm{Cl} 1.83,18)$ higher than their counter parts. Children living in houses with less than two windows were 3 times (AOR=3.18; $95 \% \mathrm{Cl} 1.07,9.5)$ more likely to have pneumonia, than their counter part children living in houses with more than two windows. Children who were carried on their parents/care takers back were about five times ( $\mathrm{AOR}=5.15 ; 95 \% \mathrm{Cl} ; 1.6,16.7)$ more likely susceptible to pneumonia than their counter part children who were not exposed to indoor air pollution resulting from use of biomass. Similarly, children who were not vaccinated were almost five times (AOR $=4.76 ; 95 \% \mathrm{Cl} 1.69,13.37$ ) more likely to develop pneumonia than children who were vaccinated at least once in their lifetime (Table 3 ).

\section{Discussion}

The present study has identified a relatively low prevalence of pneumonia among 2 -59 months old children and also pointed out certain modifiable risk factors. This figure of 2 -59 months old children pneumonia prevalence $(7.5 \%)$ is almost equivalent to the national prevalence of pneumonia (7\%), according to EDHS 2011(6). This similarity might be due to following the same assessment method to ascertain the diseases based on mothers or care takers' report. On the other hand, this finding is not in line with the findings from a cross sectional survey in Este town (7) which found the prevalence of underfive pneumonia to be significantly higher, $16.1 \%$. The possible reason for this difference could be due to the seasonal variation and topographic dissimilarity of the two study areas. Similarly, this finding is not comparable to the findings from the retrospective study in UNHCR refugee camps (8) where pneumonia accounted $17 \%$ of child morbidity. Besides the difference in methodology, the study setting, i.e. the refugee camps are the area where there is overcrowding and hence higher chance of transmission of the disease, may have accounted for the difference in the prevalence of pneumonia in children. Also, efforts to improve access to maternal and childcare services in this study area could have contributed to this low level of childhood pneumonia morbidity. The prevalence of pneumonia in children in this study setting is not consistent with the findings from a cross sectional survey in Uganda (9) where pneumonia prevalence was found to be significantly higher (53.7\%). The discrepancy in the difference in the prevalence of pneumonia could be due to the difference in the setting in which these two studies were conducted, the latter being done in the National referral hospital of Uganda. The cross sectional survey in Kuwaiti, Bangladesh (10) showed the prevalence of under-five pneumonia was estimated to be $53 \%$.

In this study, the occurrence of pneumonia was not affected by the residence. This is comparable to the findings from the cross sectional survey in Este town (7) where pneumonia prevalence was not different between urban and rural dwellers. The presence of pneumonia among under five-year children did not show statistically significant association with the educational status and occupation of parents. This finding is consistent with the findings from a case control study in Pakistan (11) where there was no a statistically significant difference in the prevalence of pneumonia between educated and none educated parents. This case control study, however, reported that maternal occupation had been found to be significantly associated with pneumonia, which is in contrary to the finding in this study. This difference could be explained by the difference in the methodology. Similarly, this finding is supported by the report from the cross sectional survey in Este town (7) where educational status and occupation of the parent did not illustrate significant association with pneumonia in children. Another case control study from 
India (12) reported that the literacy status of the father did not show any association with pneumonia in under-fives. Also, we did not find any significant difference in the occurrence of pneumonia with sex of the child. This finding is not consistent with the findings from the report of lancet 2013 (13) which showed higher occurrence of pneumonia in boys than in girls (median OR=1.3). The difference in the methodology could be the reason for this discrepancy.

In this study, there was a difference in the occurrence of pneumonia with the age of child. This finding is in line with the report from lancet 2013 (13) which revealed higher occurrence of pneumonia in children younger than 2 years of age. Similarly, the result is similar to studies conducted in Urban Areas of Oromiya Zone, Amhara Region (3) where children at age rang $2-11$ months were $85 \%$ higher chance to have pneumonia as compared to older age. Though this study showed that use of charcoal and wood for cooking was higher in the study area, there was no significant statistical association with pneumonia in under-fives. This is just the opposite findings to the cross sectional survey report in Este town (7) where there was a statistically significant association of the occurrence of pneumonia with charcoal use for cooking. On the other hand, place of cooking and place of the child during cooking were associated with pneumonia in this study. This is consistent with the Este town cross sectional survey (7) findings, where cooking in the living room and carrying the child during cooking were a significant risk factor for pneumonia.

In addition, types of latrines households use were not associated with pneumonia in 2-59 months old children in this study. This is not consistent with the WHO/UNICEF report (13) which revealed that improved latrine can for most part prevent pneumonia in children. This study could not find a significant association between pneumonia in children and current smoking habits of any household resident. This is not in line with the reports from WHO training package on health sector (14), where children whose parents smoke were $60 \%$ more affected by pneumonia. Also, this finding is not supported by the scientific articles published in Miami (15) and Poland (16) and case control study in West Africa (17) where cigarette smoke was demonstrated to be the risk factor for pneumonia in children.

The finding of this study revealed that the number of windows of the living house has a significant association with the prevalence of pneumonia in the study area; this finding is similar to the study conducted in Este town, where the finding of the study showed that indoor air pollution resulting from the use of biomass fuel for cooking has statistical association with pneumonia. Air pollutants associated with biomass fuel use may adversely affect specific and non-specific host defenses of the respiratory tract against pathogens.

Exclusive breast-feeding status of the child during the first 6 months of child's life was not found to factor pneumonia in children in the study area. This is not consistent with findings from a systematic review and meta-analysis (18) done in USA, 2013, 2011 UNICEF report (19) and the integrated action plan for prevention and control of pneumonia and diarrhea report 2013 of the WHO and UNICEF (20) where exclusive breast feeding was one of the factors that could determine the incidence and prevalence of pneumonia and mortality from pneumonia in children. This difference could be explained by the fact that 
mothers who might know that breast feeding children exclusively to the first 6 months of children's life is socially acceptable may falsely reported that their children had been breastfed exclusively during their first 6 months of age.

The presence of malnutrition among children2-59 months of age was not statically associated with the prevalence of pneumonia in the study area, this finding is not in line to studies conducted in Costa Rica and Philippines (21) which revealed a significantly higher proportion of sever pneumonic infant with first, second and third degree of malnutrition compared with normal nutritional status. A similar study conducted in Ethiopia demonstrates the fact that children with malnutrition tend to have low immunity and are vulnerable to a number of infections, including Pneumonia (22). Finally, the finding of our study revealed that vaccination status of the child has a significant association with the prevalence of pneumonia. It was least in children who were fully immunized (12.5\%) as compared to unimmunized children. Similarly an Indian study reported that non immunized infants were more prone to develop sever pneumonia (23).

\section{Limitations}

The cross-sectional survey could not help establishing temporal relationship between the possible determinants 2-59 months old children pneumonia and the outcome of interest, pneumonia among 2-59 months old children. The study selectively addressed certain factors of under-five pneumonia while various factors are found to cause the diseases.

The WHO's IMNCl is not a confirmatory gold standard diagnostic tool to surely settle pneumonia diagnosis. It was difficult to measure indoor air pollution.

\section{Conclusion}

The study identified a comparatively similar result with the national prevalence of pneumonia among children 2-59 months of age. It also came up with some modifiable risk factors of pneumonia in the study area. Risk factors associated with community acquired pneumonia in Gumay district were Age of the child, cooking foods regularly in the main house, number of windows the house is constructed with, carrying the child on the back during cooking and lack of chance to be vaccinated at least once in the child's life time.

\section{Recommendations}

Based on the findings in this study, the following recommendation were forwarded

The district Health Office should: -

- Raise awareness of the community about the adverse health effect of indoor air pollution, resulting from cooking in living house without adequate ventilation. 
- The district health office in collaboration with different sectors needs to encourage contracting kitchens separately from the living house.

- District health office should establish a strong awareness raising strategies in the community to improve proper childcares and to promote the acceptability of vaccines.

- Mothers/caregivers should keep children away from smoke during cooking.

- Households should ventilate living rooms by opening doors and windows.

\section{Abbreviations}

AIDS: Acquired Immune Deficiency Syndrome,

AOR: Adjusted Odds Ratio,

ARI: Acute Respiratory tract Infection.

CHERG: Child Health Epidemiology Reference Group,

Cl: Confidence Interval,

COR: Crude Odds Ratio,

CSA: Central Statistical Agency,

EBF: Exclusive Breast Feeding,

EDHS: Ethiopian Demographic and Health Survey,

$\mathrm{HH}$ : Household,

IMNCI: Integrated Management of Neonatal and Childhood Illness,

K:Kebele

MUAC: Middle upper arm circumference,

PBF: Partial Breast Feeding,

UNICEF: united Nations Children's Fund,

UNHCR: United Nation High Commissioner for Refugees,

WHO: World Health Organization,

WoHO: Woreda /district/ Health Office. 


\section{Declarations}

Ethics approval and consent to participate: Ethical clearance was obtained from Jimma University College Health Science and Permission letter was also obtained from Jimma Zonal Health department and Gumay district Health office. Informed consent was obtained from each respondent after explanation of the study objective. The right to withdraw from the research process at any point in time was respected. Privacy and strict confidentiality were maintained throughout the study.

Consent for publication: Not applicable Availability of data and material: All data and materials in this manuscript could be deposited in any publicly available repositories.

Conflict of interest: We declared that we have no conflict of interests.

Funding: None

Author's contribution: AT initiated the research, wrote the proposal, did data cleaning and analysis, and wrote the manuscript. DH and TK involved in the write up of the proposal, data analysis, interpretation, and manuscript writing. All authors read and approved the final manuscript.

Acknowledgement Authors are grateful to all staffs of Institute of Public Health, University of Jimma for their coordination throughout the process starting from topic selection to thesis defense. We would like to extend our gratitude to different workforces participated in the data collection and supervision. Last not list; we would like to thank Jimma zone Health office and Gumay district health office.

\section{References}

1. UNICEF. Pneumonia: the forgotten killer of children. WHO, . 2006.

2. Deribew. A, Tessema F, Girma B. Determinants of underfive mortality in Gilgel Gibe Field Research Center, Southwest Ethiopia. 2007.

3. Abel. Fekadu D, Yigzaw K, Zelalem B Determinants of Pneumonia in Children Aged Two Months to Five Years in Urban Areas of Oromia Zone, Amhara Region, Ethiopia. . 2014.

4. WHO. WHO and UNICEF. HandbookIMNCl, Integrated management of childhood illness. Geneva: WHO,. 2005.

5. Health. -metrics. The Global burden of disease study, 2010

6. Green. LW, Kreuter MW, Deeds SG, Partridge KB, Bartlett E. Health education planning: a diagnostic approach. 1980.:http://www.popline.org/node/499039

7. Gedefaw. Abeje, Mamo Wubshet, Getahun Asres. Prevalence of pneumonia among under- five children in Este town and the surrounding rural kebeles, Northwest Ethiopia; A community based cross sectional study. Science Journal of Public Health. . 2014.

8. Hershey LC. , Shannon Doocy, Jamie Anderson, Christopher Haskew, Paul Spiege and William J Moss. Incidence and risk factors for malaria, pneumonia and diarrhea in children under 5 in UNHCR refugee camps: A retrospective study. Conflict and Health. 2011. 
9. Nantanda. . Ndeezi G, Tumwine jK, and Ostergaard MS. Asthma and pneumonia among under fives at Mulago Natiuonal Referral Hospital Uganda: Is asthma under diagnosed ? 8th European Congress on Tropical Medicine and International Health: a hospital based cross sectional survey. UNIVERSITY OF COPENHAGEN,2013.

10. Jones. WG. Population dynamics and their impact on adolescents in the ESCAP region. Asia Pac Popul J 1997.

11. Fatmi. and Franklin White .A comparison of 'cough and cold' and pneumonia: risk factors for pneumonia in children under 5 years revisited. International Journal of Infectious Diseases . 2002.

12. Prasad. $d$ pore. Chandrashekhar h ghattargi, Madhavi v Rayate. Study of risk factors of acute respiratory infection (ARI) in under fives in solapur, . National Journal of Community Medicine 2010.

13. Christa. L Fischer Walker, Igor Rudan, Li Liu, Harish Nair, Evropi Theodoratou, Zulfi qar A Bhutta et al. Childhood Pneumonia and Diarrhoea : Global burden of childhood pneumonia and diarrhoea . Lancet 2013.

14. WHO Children's Health and the Environment:WHO training package for health sectorsecond-hand book and tobacco smoke and children,. 2011.

15. Jennifer. L. Thompson. NCC Pediatrics Continuity Clinic Curriculum: Pneumonia, 2013.

16. Irena. Wojsyk Banaszak and Anna Bręborowicz. Pneumonia in Children. Department of Pulmonology Pediatric Allergy and Clinical Immunology, Karol Marcinkowski University of Medical Sciences, Szpitalna, Poznań, Poland; 2013.:http://dx.doi.org/10.5772/54052.

17. O' Dempsey. T J D, McArdle T F, Morris J, Lloyd-Evans N, Baldeh I, Laurence B E, Secka O and Greenwood B M. A study of risk factors for pneumococcal disease among children in a rural area of West Africa. International Journal of Epidemiology. 1996.

18. Laura. . M Lamberti, Irena Zakarija-Grković, Christa L Fischer Walkerl, Evropi Theodoratou, Harish Nair, Harry Campbell et al. Breastfeeding for reducing the risk of pneumonia morbidity and mortality in children under two: a systematic literature review and meta-analysis. BMC Public Health 2013.

19. UNICEF Programming Guide. Infant and Young Child Feeding. Nutrition Section, Programmes, UNICEF New York. 2011.

20. WHO U The Integrated Global Action Plan for the Prevention and Control of Pneumonia and Diarrhea (GAPPD). Ending preventable death from Pneumonia and Diarrhea by 2025. WHO and UNICEF,2013.

21. Selwyn. BJ. The epidemiology of acute respiratory tract infection in young children: Comparison of findings from several developing countries. Reviews of infectious Disease 1990.

22. EDHS. Factors associated with acute respiratory infection in children under the age of 5 years: evidence from the 2011 Ethiopia Demographic and Health survey, 2011.

23. Sommer. A. Tarqotjo J, Djunacdi E. Impact of Vitamin A Supplementation on childhood mortality; a randomized controlled community trial. The Lancet, 1986.

\section{Tables}


Table 1. Characteristics of respondents, Gumay District, Jimma zone, south west of Ethiopia, March 2017(n=347 mothers and children's pair) 


\begin{tabular}{|c|c|c|c|}
\hline S.No & Variables & Number (n) & Percent (\%) \\
\hline \multirow[t]{3}{*}{1} & Educational status of the mother & & \\
\hline & Illiterates & 86 & 24.8 \\
\hline & Literates & 261 & 75.2 \\
\hline \multirow[t]{3}{*}{2} & Educational status of the Father & & \\
\hline & Illiterates & 83 & 24 \\
\hline & Literates & 264 & 76 \\
\hline \multirow[t]{5}{*}{3} & Occupation of the mother & & \\
\hline & Housewife & 268 & 77.2 \\
\hline & Civil servant & 31 & 8.9 \\
\hline & Merchant & 26 & 8.4 \\
\hline & Other & 19 & 5.5 \\
\hline \multirow[t]{5}{*}{4} & Occupation of the father & & \\
\hline & Farmer & 183 & 52.7 \\
\hline & Civil servant & 55 & 16 \\
\hline & Merchant & 60 & 17.3 \\
\hline & Other & 49 & 14 \\
\hline \multirow[t]{4}{*}{5} & Age of the child & & \\
\hline & $2-11$ months & 83 & 24 \\
\hline & $12-23$ months & 140 & 40.3 \\
\hline & $24-59$ months & 124 & 35.7 \\
\hline \multirow[t]{3}{*}{6} & Sex of the child & & \\
\hline & Male & 195 & 56.2 \\
\hline & Female & 152 & 43.8 \\
\hline \multirow[t]{3}{*}{7} & Residence & & \\
\hline & Urban & 97 & 28 \\
\hline & Rural & 250 & 72 \\
\hline \multirow[t]{4}{*}{8} & Family size & & \\
\hline & $1-3$ & 94 & 27.1 \\
\hline & $4-7$ & 206 & 59.4 \\
\hline & $>=8$ & 47 & 13.5 \\
\hline \multirow[t]{3}{*}{9} & Type of Toilet facility & & \\
\hline & Improved & 100 & 28.8 \\
\hline & Unimproved & 247 & 71.2 \\
\hline \multirow[t]{4}{*}{10} & Drinking Water source & & \\
\hline & Pipe water & 82 & 23.6 \\
\hline & Protected spring/Hand pump & 243 & 70 \\
\hline & Unprotected water & 22 & 6.3 \\
\hline \multirow[t]{4}{*}{11} & Cooking Fuel & & \\
\hline & Charcoal & 43 & 12.4 \\
\hline & Wood & 294 & 84.7 \\
\hline & Electric power & 10 & 2.9 \\
\hline \multirow[t]{3}{*}{12} & Cooking Place & & \\
\hline & Main House & 68 & 19.6 \\
\hline & Kitchen & 279 & 80.4 \\
\hline \multirow[t]{3}{*}{13} & Kitchen separated from main house & & \\
\hline & Yes & 264 & 76.1 \\
\hline & No & 83 & 23.9 \\
\hline
\end{tabular}

14 Number of windows of the main house 


$\begin{array}{lll}\text { Less than two } & 108 & 31 \\ \text { Two and above } & 239 & 69\end{array}$

15 Cleanliness of the house

$\begin{array}{lll}\text { Good } & 128 & 37 \\ \text { Not good } & 219 & 63\end{array}$

16 Location of the child during cooking

$\begin{array}{lll}\text { On cooking mother's back } & 94 & 27\end{array}$

$\begin{array}{lll}\text { Outside the cooking room } & 253 & 73\end{array}$

17 Breast feeding status during the first 6 months of the child

Exclusive Breast Feeding $\quad 205 \quad 59$

Not exclusive breast feeding $\quad 142 \quad 41$

18 Weaning time

$\begin{array}{lll}\text { Less than a year } & 139 & 40 \\ \text { More than a year } & 208 & 60\end{array}$

19 Nutritional Status of the child

$\begin{array}{lcc}\text { Normal } & 273 & 78.7 \\ \text { Malnutrition } & 74 & 21.3\end{array}$

20 History of Diarrhea in the past two weeks

$\begin{array}{lcc}\text { Yes } & 94 & 27 \\ \text { No } & 253 & 73\end{array}$

21 Awareness of the benefits of vaccination

\begin{tabular}{|cccc}
\hline & Yes & 278 & 80 \\
\hline 22 & No & 69 & 20 \\
\hline & Vaccination history of the child & & \\
\hline & Vaccinated & 287 & 82.7 \\
\hline & Unvaccinated & 60 & 27.3 \\
\hline 23 & Immunization status of the child & & \\
\hline & Fully immunized & 236 & 68 \\
\hline & Incomplete immunization & 111 & 32 \\
\hline 24 & Health seeking behavior & 293 & 84.4 \\
\hline & Yes & 54 & 15.6 \\
\hline
\end{tabular}

Table 2. Bivariate determinants association with pneumonia among under five-year children, Gumay District, Jimma zone, south west of Ethiopia, March 2017(n=347 mothers and children's pair) 


\begin{tabular}{|c|c|c|c|c|c|}
\hline & \multirow[b]{2}{*}{ Variables } & \multicolumn{2}{|c|}{ Pneumonia\% } & \multirow[b]{2}{*}{ COR (95\% CI) } & \multirow[b]{2}{*}{ P-Value } \\
\hline & & Yes & No & & \\
\hline \multirow[t]{4}{*}{1} & Age of the child & & & & \\
\hline & 2-11 months & 18.2 & 81.8 & $4.78(1.8,12.8)$ & $0.000^{* *}$ \\
\hline & $12-23$ months & 4.4 & 95.6 & $6.7(2.2,20.6)$ & 0.65 \\
\hline & 24-59 months & 2.4 & 97.6 & 1 & \\
\hline \multirow[t]{3}{*}{2} & Type of latrine facility & & & & \\
\hline & Improved & 2 & 98 & 1 & \\
\hline & Unimproved & 9.7 & 90.3 & $5.23(1.2,23)$ & $0.026^{* *}$ \\
\hline \multirow[t]{3}{*}{3} & Place of cooking & & & & \\
\hline & Main house & 25.3 & 74.7 & $4(1.78,9.24)$ & $0.001^{* *}$ \\
\hline & Kitchen & 2.6 & 97.4 & 1 & \\
\hline \multirow[t]{3}{*}{4} & Kitchen is separated from the house & & & & \\
\hline & Yes & 4 & 96 & 1 & \\
\hline & No & 18 & 82 & $5(2.23,11.6)$ & $0.000^{* *}$ \\
\hline \multirow[t]{3}{*}{5} & Number of windows & & & & \\
\hline & Less than two & 15.7 & 84.3 & $4.37(1.2,10.0)$ & $0.000^{* *}$ \\
\hline & Two and above & 4 & 96 & 1 & \\
\hline \multirow[t]{3}{*}{6} & Cleanliness of the house & & & & \\
\hline & Good & 3 & 97 & 1 & \\
\hline & Not Good & 10 & 90 & $0.29(0.1,0.86)$ & $0.025^{* *}$ \\
\hline \multirow[t]{3}{*}{7} & Location of the child during cooking & & & & \\
\hline & On cooking mother's back/besides her & 15 & 85 & $3.4(1.5,7.65)$ & $0.000^{* *}$ \\
\hline & Outside of the cooking house & 5 & 95 & 1 & \\
\hline \multirow[t]{3}{*}{8} & Breast feeding status of the child & & & & \\
\hline & Exclusive breast feeding & 4 & 96 & 1 & \\
\hline & Not exclusive breast feeding & 12.7 & 87.3 & $3.6(1.5,8.5)$ & $0.004 * *$ \\
\hline \multirow[t]{3}{*}{9} & Weaning time & & & & \\
\hline & Less than a year & 13.7 & 86.3 & $4.55(1.8,11.13)$ & $0.001^{* *}$ \\
\hline & One year and above & 3.4 & 96.6 & 1 & \\
\hline
\end{tabular}

10 Nutritional status of the child

\begin{tabular}{lcccc} 
Normal & 3.6 & 96.4 & 1 & \\
\hline Malnutrition & 23 & 77 & $7.4(3.2,17.2)$ & $0.000^{* *}$
\end{tabular}

11 Diarrhea in the past two weeks

\begin{tabular}{|c|c|c|c|c|}
\hline Yes & 14.4 & 85.6 & $3.17(1.41,7.13)$ & $0.005^{* *}$ \\
\hline No & 5 & 95 & 1 & \\
\hline
\end{tabular}

12 Awareness of the benefits of vaccine

Yes

$\begin{array}{lll}5.8 & 94.2 & 1\end{array}$


85.5

$9.8(4.2,23)$

$0.027^{* *}$

13 Vaccination status of the child

Vaccinated

Unvaccinated

14 Immunization status of the child

Fully immunized

Incomplete immunization

15 Health seeking behavior

Yes

No
$3.8 \quad 96.2$

1

$25 \quad 75$

298

1

$19 \quad 81$

$11(4,30)$

$0.000^{* *}$

$3.8 \quad 96.2$

1

$27.8 \quad 72.4 \quad 2.7(1.2,6.4)$

$0.000^{* *}$

Table 3 Multivariate association of pneumonia among under five-year children, Gumay District, Jimma zone, south west of Ethiopia, March 2017(n=347 mothers and children's pair)

Variables

1 Age of the child

02 - 11 months

12 - 23 months

24 - 59 months

\section{AOR (95 \% CI) P-Value}

4.78(1.8,12.8) $\quad 0.002$

$6.7(2.1,21) \quad 0.001$

1

\section{Number of windows}

Two and less windows $\quad 4.08(1.51,11.0) \quad 0.006$

More than two windows

1

3 Nutritional status

Normal

1

Malnutrition

$4.81(1.79,13) \quad 0.002$

4 Vaccination status of the child

Vaccinated

Unvaccinated
1

$4.34(1.65,11.41) \quad 0.003$ 